\title{
ERRATA
}

\section{A FLEXIBLE AND FAULT TOLERANT QUERY-REPLY SYSTEM BASED ON A BAYESIAN NEURAL NETWORK}

\author{
[Int. J. Neural Syst. Vol. 4, No. 3 (September, 1993) 257-267)]
}

\author{
ANDERS HOLST and ANDERS LANSNER \\ SANS - Studies of Artificial Neural Systems, Department of Numerical Analysis and Computing Science \\ Royal Institute of Technology S-100 44 Stockholm, Sweden
}

On page 257, the third line from bottom of the left column should read:

"..., it is designed as a query-reply system, ${ }^{14,18,19}$ i.e. given ..."

Two references should also be added to the paper:

18. M. Stensmo, B. Levin and A. Lansner [1989] "A question driven classification system usidng a neural network model," in Proc. Nordic Symposium on Neural Computing, Espoo, Finland.

19. M. Stensmo, A. Lansner and B. Levin, "A query-reply system based on a recurrent Bayesian artificial neural network," in Proc. ICANN-91, eds. T. Kohonen, K. Mkisara, O. Simula and J. Kangas (North-Holland), pp. 459-464. 